\title{
Factorial design, processing, characterization and microstructure analysis of PIP-based C/SiC composites
}

\author{
SURESH KUMAR*, M BABLU, SHRIRAM JANGHELA, M K MISRA, RAGHWESH MISHRA, \\ ASHOK RANJAN and N ESWARA PRASAD
}

Directorate of Ceramics and CMCs, DMSRDE, Kanpur 208013, India

*Author for correspondence (sureshtanwar@ rediffmail.com)

MS received 5 April 2016; accepted 26 October 2017; published online 2 February 2018

\begin{abstract}
Polymer impregnation and pyrolysis (PIP) process-based $\mathrm{C} / \mathrm{SiC}$ composites are fabricated using the in-house synthesized methyl-polycarbosilane (PCS). Two-level factorial design matrix is employed to carry out experiments to study the effect of four factors on flexural strength of the composite. Total sixteen sets of composite samples are fabricated. Response table, normal probability plot, ANOVA and regression analysis are carried out to determine the statistical significant factors. Composite density $(\rho)$, fibre volume fraction $\left(V_{\mathrm{f}}\right)$ and pyrolysis temperature $(T)$ are found to be statistically significant, while softening point (SP) of the PCS and interaction of these four factors are found insignificant. Higher levels of the density and $V_{\mathrm{f}}$ have shown positive effect, while the pyrolysis temperature has negative effect on the flexural strength of the composites. Flexural strength was found to be in the range of 374-592 MPa depending on the process parameters. The mechanical behaviour of the composites at different process conditions was explained with the help of their microstructures.
\end{abstract}

Keywords. Ceramic composite; PIP; factorial design; mechanical properties; microstructure.

\section{Introduction}

Continuous fibre-reinforced silicon carbide matrix composites are potential candidate for high temperature applications [1-3]. Silicon carbide matrix-based composites are fabricated with chemical vapour deposition and chemical vapour impregnation (CVD/CVI), polymer impregnation and pyrolysis (PIP) and liquid silicon infiltration (LSI) processes [4]. $\mathrm{PIP}$ process is preferred for fabricating large size $\mathrm{C} / \mathrm{SiC}$ composite products over CVI and LSI due to its high production rate and less processing cost [4]. Pyrolysis temperature and rate of heating were reported to have significant effect on the properties of the $\mathrm{C} / \mathrm{SiC}$ composite $[5,6]$. Also, the mechanical properties and their dependence on the process parameters are found to be significantly different from one study to the other [5-7]. Parameters, like fibre architecture, fibre type, polycarbosilane type and processing methodology used by different researchers predict different results [7-9]. Generally, appropriate and engineered interface was used to obtain desired properties of PIP-based ceramic matrix composites $[10,11]$. The matrix cracks propagate through the matrix and get deflected around the fibre by the weak interface or interphase [12]. Interface can be applied easily on the stand alone fibrous preforms; while, it becomes almost impossible to apply on the fibre tow spools, which have to be used for certain processing like filament winding. $\mathrm{C} / \mathrm{SiC}$ composite products like rocket nozzle and other symmetrical shapes can be processed easily using filament winding technique compared to the other standard processing methods. These $\mathrm{C} / \mathrm{SiC}$ composite products and their fabrication processes have to be optimized without employing the interface.

Moreover, the ceramic composites where matrix is porous in nature, similar to the one in PIP-based C/SiC composites, cracks in the matrix lack stress singularity and propagate by the means of progressive failure of the cell walls surrounding the pores when adequate load is applied. In this manner, the reinforcing fibres are not subjected to a stress singularity from an approaching matrix crack and failure gets resist due to superior strength of the fibre relative to the weaker matrix and the relative influence of the interface becomes less important $[12,13]$. Therefore, for the PIP-based C/SiC composites, parameters acquire considerable significance, which not only affect interface characteristics, but improve the mechanical properties significantly.

Design of experiments (DOE) is a strong tool to identify the relative importance of the individual process parameters and also to study their interaction effects [14]. DOE-based optimization needs large number of experiments [14]. Therefore, it is not that popular for the long lead time fabrication processes like PIP-based $\mathrm{C} / \mathrm{SiC}$ composites. However, it is desirable to understand the relative effect of the process parameters and their interactions before selecting a set of process parameters to fabricate a specific $\mathrm{C} / \mathrm{SiC}$ composite product. This is attempted precisely in the present work by carrying out the screening experiments following DOE to determine the relative effect of the selected parameters and their interactions on flexural strength of the UD C/SiC composites. The composites would be fabricated using the 
in-house synthesized polycarbosilane (PCS) without employing the interface to build a base for the near future filament winding process aimed for the rocket nozzle. The critical process parameters would be identified using response table, normal probability curve, ANOVA and regression analysis. Additionally, the mechanical behaviour of the composites fabricated at different sets of parameters would be explained with their microstructure.

\section{Factorial design of experiments}

Physical properties of the composites like fibre properties, preform type, fibre volume fraction $\left(V_{\mathrm{f}}\right)$, density and specimen size influence the mechanical properties significantly. For a given set of the physical properties, the processing parameters like pyrolysis temperature, rate of heating and ceramic yield of the starting precursor, etc. are equally responsible for obtaining the desired mechanical and thermal properties [18-20]. Two-level, full fractional design of experiments was employed to determine the relative effect of the important physical and process parameters.

\subsection{Scheme of investigation}

For selecting the process parameters, which have significant effect on flexural properties of the PIP-based C/SiC composites without employing the interface/interphase, the following steps were used:

(i) identifying the important factors, which influence the mechanical properties of the $\mathrm{C} / \mathrm{SiC}$ composites;

(ii) fixing the upper and lower limits of the identified factors;

(iii) developing the experimental design matrix using factorial design of experiments;

(iv) conducting the experiments as per the design matrix;

(v) assessing the real or chance effect of the factors by constructing response table and normal probability plot;

(vi) analysing the results using analysis of variance (ANOVA);

(vii) developing linear expression for flexural strength as a function of the significant factors.

2.1a Identifying the important factors: Based on the literature [17,21,22], the following independently controllable process variables were identified, which have significant influence on mechanical properties of the $\mathrm{C} / \mathrm{SiC}$ composite:

(i) softening point of PCS (SP): it controls the ceramic yield and extent of matrix shrinkage;

(ii) ultimate pyrolysis temperature $(T)$ : it controls the type of phases of the matrix and fibre/matrix surface reaction;

(iii) fibre volume fraction $\left(V_{\mathrm{f}}\right)$ : it controls the overall strength of the composite matrix; shrinkage and pore size; (iv) composite density $(\rho)$ : it indirectly reflects the porosity which acts as a defect and influence the load-bearing capability of the composites.

2.1b Upper and lower limits of identified factors: Based on the literature and practical feasibility, the upper and lower limits of identified factors are found to be:

(i) The ceramic precursors reportedly used for PIP-based $\mathrm{C} / \mathrm{SiC}$ composites have different ceramic yields and softening points [17,21], but the composite properties are reported to be different. This could be due to different PCS or due to some unidentified variables. PCS having higher ceramic yield or high softening point is preferred to minimize the number of infiltration and pyrolysis cycles, but high SP PCS would have lesser number of $\mathrm{Si}-\mathrm{H}$ reactive sites known for the matrix cross-linking. Lower cross-linking might results in poor inter-laminar shear stress (ILSS) and can lead to composite delamination during pyrolysis. Very high SP PCS would not be suitable for filament winding process, while very low softening point PCS would have low ceramic yield. Hence, SP of the PCS was set as $110-120^{\circ} \mathrm{C}$ (low level) and $220-250^{\circ} \mathrm{C}$ (high level). For the filament winding process, PCS having SP between 110 and $250^{\circ} \mathrm{C}$ is considered appropriate. Therefore, for the lower level, SP is kept at $110-120^{\circ} \mathrm{C}$, while for the higher level, it is maintained at $220-250^{\circ} \mathrm{C}$.

(ii) Pyrolysis temperature controls the microstructure and phase of the charred PCS. Many researchers have fabricated PIP-based ceramic composites by pyrolysing them between 1400 and $1600^{\circ} \mathrm{C}$. Therefore, ultimate pyrolysis temperature was maintained at $1400^{\circ} \mathrm{C}$ as lower level and $1600^{\circ} \mathrm{C}$ as higher level.

(iii) $V_{\mathrm{f}}$ has an important role to achieve the desired mechanical properties. Beyond a certain $V_{\mathrm{f}}$, the reinforcement becomes ineffective due to non-uniform load transfer in association with the fragmented matrix obtained in PIP-based $\mathrm{C} / \mathrm{SiC}$ composites. Considering the practical feasibility and to fabricate composites with reasonable mechanical strength, $V_{\mathrm{f}}$ was fixed at 40 and $60 \%$ for the lower and higher levels, respectively.

(iv) Mechanical properties of the composites get influenced greatly by their density. It is very important for the PIP-based composites as the maximum attainable density of the composite depends on the size of the composite. Small size composite components can be densified to the higher densities, e.g., even up to $1.9 \mathrm{~g} \mathrm{~cm}^{-3}$, while the thicker and larger components cannot be densified in similar number of infiltration cycles. Sometimes, fabricator has to make a balance in the required number of infiltration cycles and density. Normally, $\mathrm{C} / \mathrm{SiC}$ composites with a minimum density of about $1.7 \mathrm{~g} \mathrm{~cm}^{-3}$ offer a reasonable good strength 
Table 1. Lower and upper levels of the process parameters selected for analysis.

\begin{tabular}{lcc}
\hline Parameters & Low value $(-1)$ & High value $(+1)$ \\
\hline $\begin{array}{l}\text { SP: PCS softening } \\
\text { point }\left({ }^{\circ} \mathrm{C}\right)\end{array}$ & 100 & 250 \\
$\begin{array}{l}T: \text { pyrolysis } \\
\text { temperature }\left({ }^{\circ} \mathrm{C}\right)\end{array}$ & 1400 & 1600 \\
$\begin{array}{l}V_{\mathrm{f}}: \text { fibre vol. fraction } \\
(\%)\end{array}$ & 40 & 60 \\
$\rho:$ composite density & 1.5 & 1.9 \\
$\left.(\mathrm{~g} \mathrm{~cm})^{-3}\right)$ & & \\
\hline
\end{tabular}

Table 2. Full factorial design experimental matrix for four parameters.

\begin{tabular}{lrrr}
\hline & \multicolumn{3}{c}{ Factors } \\
\hline SP & $T$ & $V_{\mathrm{f}}$ & \multicolumn{1}{c}{} \\
\hline-1 & -1 & -1 & -1 \\
-1 & -1 & -1 & 1 \\
-1 & -1 & 1 & -1 \\
-1 & -1 & 1 & 1 \\
-1 & 1 & -1 & -1 \\
-1 & 1 & -1 & 1 \\
-1 & 1 & 1 & -1 \\
-1 & 1 & 1 & 1 \\
1 & -1 & -1 & -1 \\
1 & -1 & -1 & 1 \\
1 & -1 & 1 & -1 \\
1 & -1 & 1 & 1 \\
1 & 1 & -1 & -1 \\
1 & 1 & -1 & -1 \\
1 & 1 & 1 & 1 \\
1 & 1 & 1 & \\
\hline
\end{tabular}

$[19,20]$. Therefore, composite density of $1.5 \mathrm{~g} \mathrm{~cm}^{-3}$ was selected as lower level, while $1.9 \mathrm{~g} \mathrm{~cm}^{-3}$ is selected for the upper level to cover the useful density range and to determine its quantitative effect on the flexural strength.

2.1c Developing the experimental design matrix using design of experiments: To conduct the experiments, twolevel full factorial design of experiment is used. Identified factors and their lower and upper limits are shown in table 1 .

All possible combinations of these four factors were included, so that there are $2^{n}$ (where $n$ refers to the number of factors) number of experiments [20]. Therefore, 16 experiments were conducted. The design matrix adopted for the present study for carrying out 16 experiments is shown in table 2 .

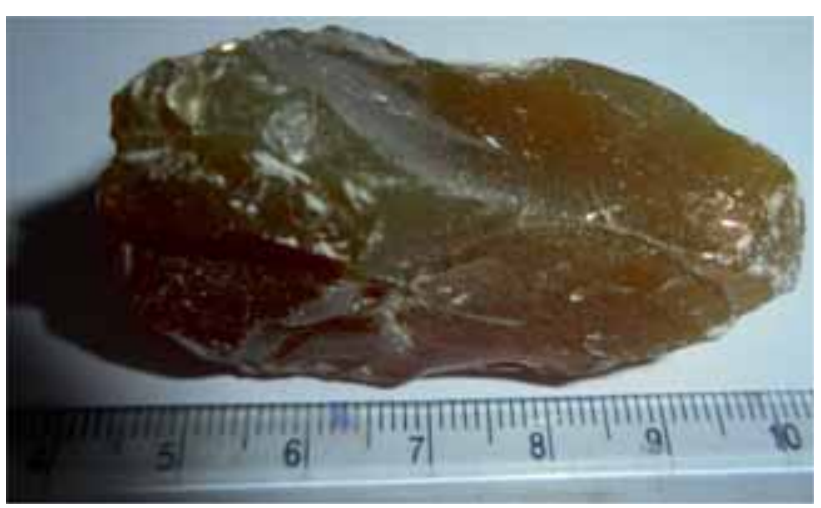

Figure 1. PCS used for the $C_{\mathrm{f}} / \mathrm{SiC}$ composite fabrication.

\section{Experimental}

\subsection{Polycarbosilane synthesis}

Methyl-polycarbosilanes (PCS) were synthesized at $250-400^{\circ} \mathrm{C}$ following the DMSRDE/DRDO patented process [24]. PCS fractions with softening point in the range of $110-120$ and $220-250^{\circ} \mathrm{C}$ were used as silicon carbide precursor corresponding to the low and high levels, respectively (table 2). A typical photograph of the solid PCS piece with $\mathrm{SP} \approx 240^{\circ} \mathrm{C}$ is shown in figure 1 . Detailed characteristics of the PCS are available elsewhere [24].

\subsection{Composite fabrication process}

Carbon fibre ( $3 \mathrm{~K}$ or $6 \mathrm{~K}$ tows and their combinations) with an average strength of $3.2 \mathrm{GPa}$ and modulus of $240 \mathrm{GPa}$ (equivalent to T300 grade) were used as reinforcement. Based on the fibre volume fraction requirements, several tows were wound on a graphite fixture with slots of 5 or $10 \mathrm{~mm}$ width. Length of the each slot was fixed, i.e., $250 \mathrm{~mm}$ to get composite of $250 \mathrm{~mm}$ long. On the same fixture, multiple slots were made to obtain multiple numbers of UD fibrous preforms in a single process cycle. PCS resin solution was prepared using PCS and divinylbenzene (DVB) in a ratio of 5:1 (wt/wt basis). Specific grade PCS was used as per the requirement (table 2). The resin solution was further diluted by adding petroleum ether (50:50, vol/vol). Few drops of platinum Speier's catalyst were also added in the solution. The preform along with the graphite fixture was impregnated with the resin solution using the standard vacuum infiltration technique. The fixture was taken out from the resin solution and placed between the metallic plates. Different height spacers $(0.9-1.7 \mathrm{~mm})$ were kept between the plates used to control the thickness of the composite. The height of the spacers was decided based on fibre-volume fraction requirement. The plates with the resin infiltered preforms were heated slowly up to $300^{\circ} \mathrm{C}$. Simultaneously, pressure was applied by a hydraulic press to obtain UD carbon fibrereinforced PCS composite strips of the desired $V_{\mathrm{f}}$. Controlled $V_{\mathrm{f}}(40$ and $60 \%$ ) preforms were fabricated by varying the 
number of tows and the thickness of the spacers for fabricating the composite sample of width $(5-10 \mathrm{~mm}$ for the different batches). Ratio of the carbon fibre volume in the composite to the physical volume of the composite is taken as $V_{\mathrm{f}}$, but for the general discussions, $V_{\mathrm{f}}$ is used in percentage form. Procedure for estimating the fibre-volume fraction in a given composite sample is described in Appendix 1. The cured composite were pyrolysed under vacuum at predecided temperature (table 2) for $2 \mathrm{~h}$. For all the experiments, heating was carried out at

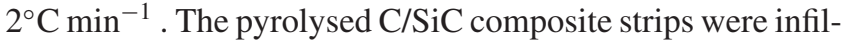
trated again with the specific resin solution using vacuum infiltration technique followed by pressurizing the infiltration system up to six bar with inert gas. The composite strips were taken out and heated up to $300^{\circ} \mathrm{C}$ in inert furnace and then, pyrolysed at the designated temperature. Infiltration and pyrolysis cycles were repeated several times to obtain $\mathrm{C} / \mathrm{SiC}$ composite strips of density 1.5 and $1.9 \mathrm{~g} \mathrm{~cm}^{-3}$. Density of the composite was determined using the standard Archimedes principle.

\subsection{Flexural strength (3-point bend strength)}

Flexural strength of the composite strips corresponds to all the experiments, and was determined over a fixed span of $20 \mathrm{~mm}$ with a crosshead speed of $0.5 \mathrm{~mm} \mathrm{~min}^{-1}$. Flexural strength was calculated as per the ASTM standard C-1341. A minimum number of 10 strips were tested corresponding to each experiment. The testing was carried out at an Instron machine (model 5967) using the appropriate fixtures. Microstructure of the tested composite strips was studied using scanning electron microscope (SEM, JEOL, JSM 6010LA).

\section{Results and discussion}

\subsection{PCS analysis}

Using the procedure described by Saxena and co-workers [24], controlled molecular weight and softening temperature, PCS were synthesized in adequate quantity. The synthesized PCS is pale golden yellow in colour and amorphous glassy brittle pieces of size about $50 \mathrm{~mm}$ (figure 1). High softening point PCS was designated as HSP-PCS, while the low softening point PCS is designated as LSP-PCS. The average molecular weight number of the HSP-PCS was found to be 1850 , where $M_{\mathrm{w}} / M_{\mathrm{n}}$ was 5.0 , while for the LSP-PCS, it was found to be 1250 with $M_{\mathrm{w}} / M_{\mathrm{n}}=5.36$. Density of the HSPPCS crystals was found to be about $1.0 \mathrm{~g} \mathrm{~cm}^{-3}$. FTIR analysis revealed that the PCS primarily contains $\mathrm{C}-\mathrm{H}, \mathrm{Si}-\mathrm{CH}_{3}, \mathrm{Si}-$ $\mathrm{CH}_{2}-\mathrm{Si}$ and $\mathrm{Si}-\mathrm{H}$ bonds. The peaks corresponding to these bonds were found in both the grades of PCS. The peaks at 2956 and $2896 \mathrm{~cm}^{-1}$ are recognized as the $\mathrm{C}-\mathrm{H}$ bond stretching of $\mathrm{Si}-\mathrm{CH}_{3} ; 2092 \mathrm{~cm}^{-1}$ of $\mathrm{Si}-\mathrm{H}$ stretching; the peak located at $1411 \mathrm{~cm}^{-1}$ is attributed to $\mathrm{CH}_{2}$ deformation of $\mathrm{Si}-\mathrm{CH}_{2}-\mathrm{Si}$; $1248 \mathrm{~cm}^{-1}$ corresponds to $\mathrm{Si}-\mathrm{CH}_{3}$ stretching and $1043 \mathrm{~cm}^{-1}$ corresponds to $\mathrm{Si}-\mathrm{CH}_{2}-\mathrm{Si}$. However, $\mathrm{Si}-\mathrm{O}-\mathrm{Si}$ bond peak is

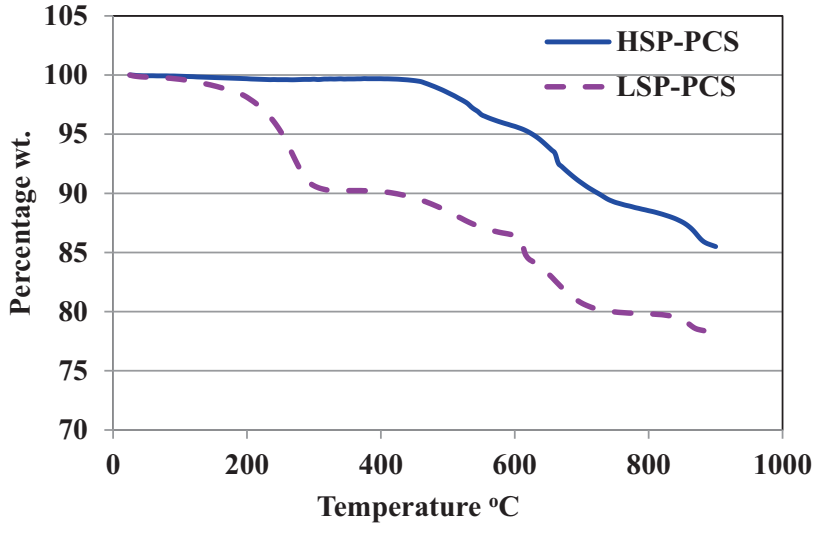

Figure 2. TGA analysis of the PCS used for $C_{\mathrm{f}} / \mathrm{SiC}$ composite.

also evident at around $1100 \mathrm{~cm}^{-1}$. Further details of the FTIR of the PCS are available elsewhere [24,25]. TGA was carried out in an inert atmosphere to determine the ceramic yield of PCS at $900^{\circ} \mathrm{C}$. Ceramic yield of HSP-PCS was found to be $85 \%$, while of LSP-PCS, it was $78 \%$ (figure 2). In another separate experiment, HSP-PCS and LSP-PCS samples were heated up to 1400 and $1600^{\circ} \mathrm{C}$ in vacuum. For HSP-PCS, the ceramic yield was found to be 68.0 and $64.4 \%$ at 1400 and $1600^{\circ} \mathrm{C}$, while for LSP-PCS, it was 61.3 and $57.0 \%$ at 1400 and $1600^{\circ} \mathrm{C}$, respectively. From figure 2, it is evident that the HSP-PCS loses only about $2 \%$ of its mass between 100 and $440^{\circ} \mathrm{C}$. The sample weight decreased rapidly until about $800^{\circ} \mathrm{C}$. Decomposition rate of the LSP-PCS was higher than the HSP-PCS, it is interpreted due to the presence of lower molecular weight PCS fraction, which did not convert into the ceramic char and escaped as gas. The rapid weight loss is interpreted as the decomposition of the side chains of the PCS and this has led to the shrinkage of the resulting $\mathrm{SiC}$ matrix. Although the shrinkage increases the density of the matrix, but due to fibre network, the matrix does not shrink uniformly. Initially, PCS occupies entire space that exist between the reinforcing carbon filaments. During pyrolysis, PCS converts into $\mathrm{SiC}$ and loses up to $20 \%$ mass (figure 2). Also, density increases from about 1.0 (PCS) to about $3.2 \mathrm{~g} \mathrm{~cm}^{-3}$ (SiC). Hence, volumetric shrinkage of the order of $82 \%$ takes place. Due to this shrinkage and CTE mismatch between carbon fibres and $\mathrm{SiC}[26,27]$; large matrix cracks are visible (figure 3a). However, the cracks generated in the matrix get filled in subsequent infiltration cycles. Unapproachable cracks remain unfilled (figure $3 b$ ) and considered as close porosity. Such cracks might act as defects under load.

\subsection{Densification of $\mathrm{C} / \mathrm{SiC}$ composite}

Owing to the large difference in the ceramic yields, the SP of PCS and pyrolysis temperature is considered to have strong effects on the densification efficiency. Rate of densification was higher with HSP-PCS at $1400^{\circ} \mathrm{C}$. At $1400^{\circ} \mathrm{C}$, with HSPPCS, the composites have attained density up to $1.9 \mathrm{~g} \mathrm{~cm}^{-3}$ 

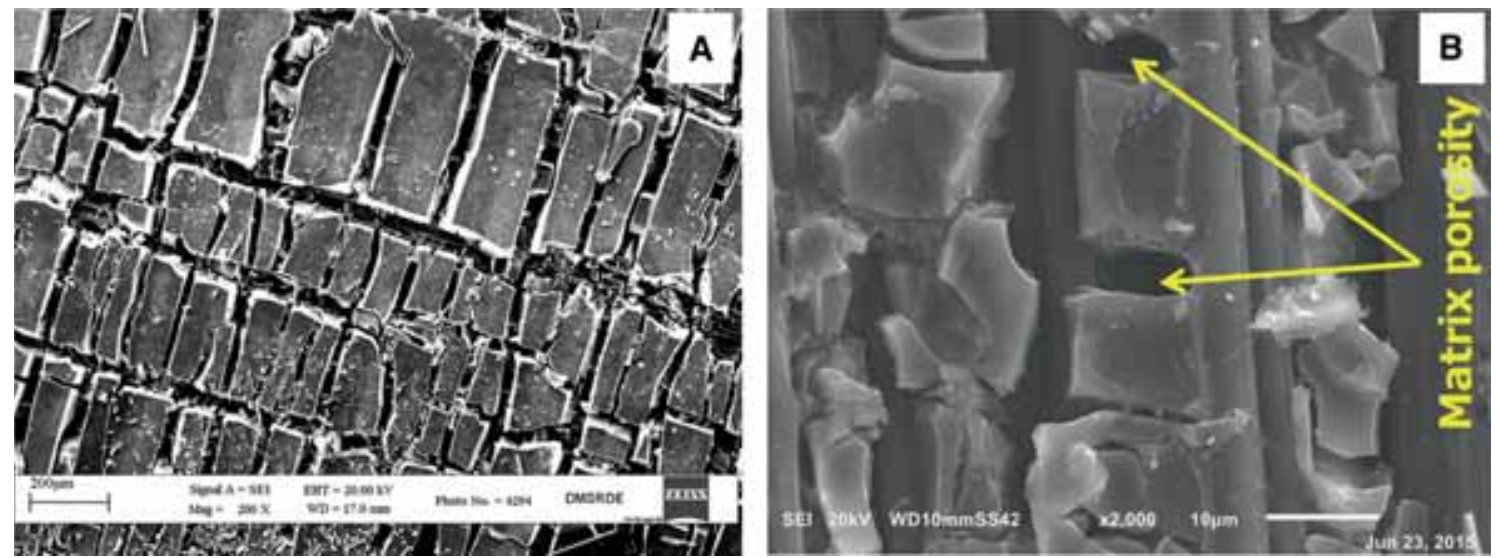

Figure 3. Microcracks developed in the matrix during composite pyrolysis.

after six infiltrations and pyrolysis cycles, while with the LSPPCS, it took eight cycles to achieve the similar density level. The number of infiltration and pyrolysis cycles were eight and 11 when the pyrolysis was carried out at $1600^{\circ} \mathrm{C}$ using the HSP-PCS and LSP-PCS, respectively. The high densification rate with HSP-PCS was inferred due to the higher ceramic yield of the precursor. Along with the experimental observation, it is reported that there is a weight loss between 1400 and $1600^{\circ} \mathrm{C}$ during pyrolysis of the PCS [28]. The weight loss is interpreted due to escape of $\mathrm{CO}(\mathrm{g})$ [28], which decreases the effective ceramic yield of the precursor. Therefore, at $1600^{\circ} \mathrm{C}$, density of the composite was relatively lower compared to the one pyrolysed at $1400^{\circ} \mathrm{C}$ after the same number of infiltration cycles.

\subsection{Composite characterization}

4.3a Phase analysis: XRD patterns of the composites pyrolysed at 1400 and $1600^{\circ} \mathrm{C}$, respectively, are shown in figure 4. XRD diffraction patterns at both the levels of the heat treatment are similar. All major peaks are visible at both the levels. However, the peak intensities are little bit different. The peak at $2 \theta=26.723^{\circ}$ is due to graphitic carbon fibre reinforcement, which corresponds to the lattice plane (002) as per JCPDC 89-8487, which is present at both the temperature levels. At $1400^{\circ} \mathrm{C}$, the major diffraction peaks are visible at $2 \theta=26.723,35.823,60.198 \mathrm{Si}-\mathrm{CH}$ and $\mathrm{Si}-\mathrm{CH} 71.924^{\circ}$. There are some smaller peaks present at $2 \theta=34.159,37.5,41.569$ and $45.612^{\circ}$. The peak positions were analysed vis-a-vis JCPDC: 75-0254 ( $\beta$-SiC polymorph) and JCPDC: $75-1541$ (6H-SiC polymorph) data and it was found that all the peak positions are practically matching with $6 \mathrm{H}-\mathrm{SiC}$ polymorph peaks at $34.185,35.751,41.502,60.177$, 71.975 and $75.615^{\circ}$, corresponding to the lattice planes of (101), (006), (167), (108), (202) and (0012). However, some peaks given in JCPDC: 75-0254 ( $\beta$-SiC polymorph), particularly, at 35.655 and $59.992^{\circ}$ could have merged with the near

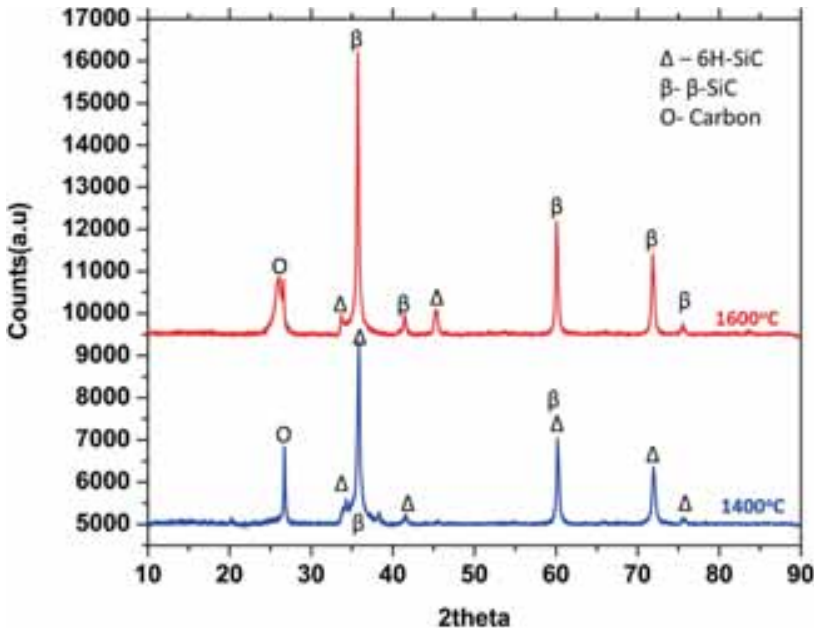

Figure 4. XRD analysis of the composite at lower and upper levels of heat-treatment temperature.

by $6 \mathrm{H}-\mathrm{SiC}$ peaks as both polymorph peaks are very close to each other.

At $1600^{\circ} \mathrm{C}$, the major peaks identified from the XRD graph are at $2 \theta=25.995,35.706,60.055$ and $71.82^{\circ}$ and some minor peaks were at $2 \theta=33.64,41.439,45.261$ and $75.512^{\circ}$. The peaks at $35.706,41.439,60.055,71.82$ and $75.512^{\circ}$ matches well with the $\beta-\mathrm{SiC}$ polymorph correspond to the lattice planes of (111), (104), (220), (311) and (222), while the peaks at 33.64 and $45.261^{\circ}$ are matching with the $6 \mathrm{H}-\mathrm{SiC}$ polymorphs corresponding to the lattice planes (101) and (105). It is evident from the two level heat treatments that the crystal phase formation depends on the temperature. At $1400^{\circ} \mathrm{C}$, the matrix mainly consists of $6 \mathrm{H}-\mathrm{SiC}$ polymorphs, while at $1600^{\circ} \mathrm{C}$, the matrix found to be mainly of $\beta-\mathrm{SiC}$ polymorphs. $\beta-\mathrm{SiC}$ and $6 \mathrm{H}-\mathrm{SiC}$ polymorphs are present at both the levels. Similar XRD patterns are reported elsewhere [7,8]. Also, the peaks become sharper at $1600^{\circ} \mathrm{C}$, which indicate that the crystal grain size of the $\mathrm{SiC}$ matrix might be increasing 
Table 3. Average flexural stress values.

\begin{tabular}{lllccllll}
\hline Expt. no. & \multicolumn{1}{c}{1} & \multicolumn{2}{c}{2} & \multicolumn{2}{c}{3} & \multicolumn{1}{c}{4} & \multicolumn{1}{c}{5} & \multicolumn{1}{c}{6} \\
\hline FS (MPa) & $425 \pm 17$ & $495 \pm 23$ & $450 \pm 21$ & $571 \pm 26$ & $374 \pm 13$ & $441 \pm 16$ & $409 \pm 19$ & $468 \pm 20$ \\
Expt. no. & 9 & 10 & 11 & 12 & 13 & 14 & 15 & 16 \\
FS (MPa) & $399 \pm 15$ & $525 \pm 18$ & $461 \pm 12$ & $592 \pm 23$ & $401 \pm 17$ & $489 \pm 17$ & $393 \pm 19$ & $487 \pm 20$ \\
\hline
\end{tabular}

with temperature. The phase composition might have some influence on the properties, which would be discussed later.

4.3b Flexural properties: About 100 specimens were tested, and correspond to the planned 16 different experiments where a minimum of six samples were tested at each set of the process conditions. Corresponding to the each experiment, the arithmetic mean average flexural stress values obtained, and are given in table 3.

\subsection{Assessing the factors and their effects}

Effect of the factors on flexural strength is assessed using the following sequence of analysis:

(i) by construction of response table;

(ii) by normal probability plot;

(iii) by two-way analysis of variance (ANOVA);

(iv) regression analysis.

4.4a Response table: Impact of the factors on flexural strength was performed by constructing response table; the table is used to simplify the calculations required to analyse the flexural strength data (table 3). In response table, the effect of a factor on a response variable (flexural strength) is the change in the response when the factor varies from its low level to its high level. The complete response table for a 2 level, 16 runs, full factorial experimental design is shown in table 4 . If the effect of a factor is $>0.0$, the average response of the factor is higher for the high level than for the low level. However, if the estimated effect is $<0.0$, it indicates that the average response is higher at low level of the factor than at its high level. If the effect for a factor is very small, then it might be due to random variation rather a 'real' factor effect. Effects of SP, $V_{\mathrm{f}}$ and $\rho$ were found to be $>0.0$, while that of $T$ is $<0.0$. Apart from the direct effect of the factors, their interaction effects were also computed (table 4). From the response table, it is apparent that the effect of some of the factors is larger than the other. But, it is not clear, whether these effects are 'real' or 'chance'. To categorize the 'real' effects, normal probability plot was used.

4.4b Normal probability plot: Normal plot is a graphical technique based on 'central limit theorem'. The procedure for constructing the normal probability plot is given elsewhere [29]. The effect of the factors and their interactions were arranged in ascending order (table 5). Minimum effect value was assigned as rank one, while the maximum effect was assigned rank $N$, where $N$ is the total number of factors and their interactions in this study. Probability of the $i$ th rank effect was computed using the equation $P_{i}=100(i-0.5) / N$; where $i$ is the rank order. Normalized probability curve is plotted between the effect and probability (figure 5). As per the normal probability plot, the points emerge to be far away from the straight line fitted to the middle group of points signify the estimated factors. These factors are likely to represent the 'real' factor effects on the response variable. On the other hand, the points which are close to the line, fitted to the middle group of points represent the factors with insignificant effect on the response variable. From figure 5, it is evident that the factors $T, V_{\mathrm{f}}$ and $\rho$ are fairly away from the straight line, while all other factors and their interaction effects fall on the straight line. Therefore, $T, V_{\mathrm{f}}$ and $\rho$ are emerged out to be significant factors to achieve the desired flexural strength of the $\mathrm{C} / \mathrm{SiC}$ composites. Normal probability plot (figure 5) indicates the relative significance of the factors, but it does not provide a clear criterion how do we measure amount of departure from the straight-line pattern. ANOVA was used in support to classify the significant factors [30].

4.4c Analysis of variance: ANOVA allocates variability in to identifiable sources of variation and the associated degrees of freedom in an experiment. In statistics, for analysing the significant effect of the factors on the quality characteristic, $F$-test is used. The $F$-value is a ratio of two independent estimates of an experimental error, which is used to determine the statistical significance of the process factors. Associated with this ratio is a $P$-value, which quantifies the probability of making an error by associating an effect with a given factor. The $P$-value also provides the exact level of significance of a hypothesis test [31]. In ANOVA, the $P$-value determines whether a model and model terms are significant $(P<0.05)$ or insignificant $(P>0.05)$. ANOVA was performed for the data given in tables 2 and 3 using the standard inbuilt programme in MATLAB. Results of ANOVA analysis for the flexural strength are shown in table 6 . This analysis is carried out for a level of significance of $5 \%$, i.e., for a level of confidence of $95 \%$. From the ANOVA results, it may be concluded that the factors, $\rho, T, V_{\mathrm{f}}$ and interaction of $T$ and $V_{\mathrm{f}}\left(T * V_{\mathrm{f}}\right)$ 


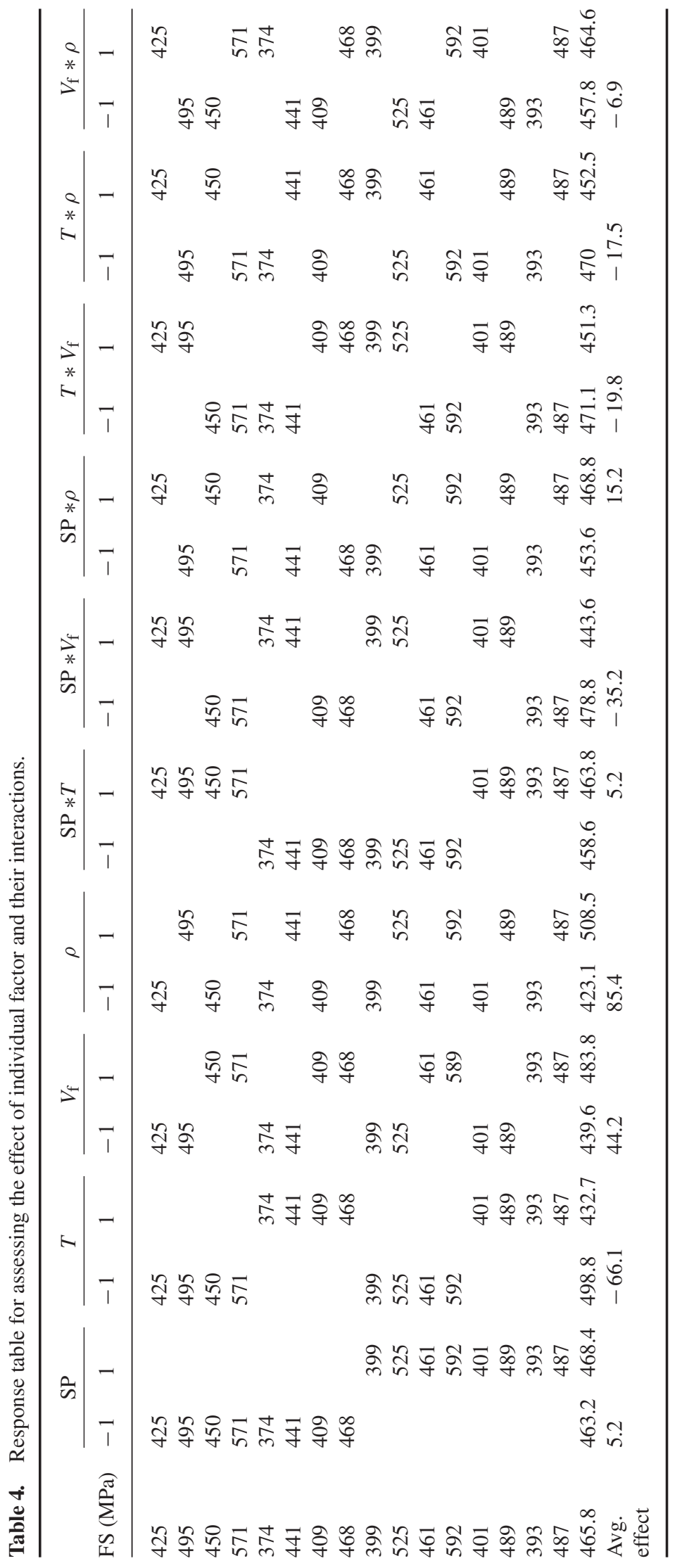


Table 5. Calculations for normal probability plot.

\begin{tabular}{lccc}
\hline Factor & Effect & Rank & Probability \\
\hline$T$ & -66.1 & 1 & 5 \\
$\mathrm{SP} * T$ & -35.2 & 2 & 15 \\
$T * V_{\mathrm{f}}$ & -19.8 & 3 & 25 \\
$T * \rho$ & -17.5 & 4 & 35 \\
$V_{\mathrm{f}} * \rho$ & -6.8 & 5 & 45 \\
$\mathrm{SP}$ & 5.1 & 6 & 55 \\
$\mathrm{SP} * T$ & 5.2 & 7 & 65 \\
$\mathrm{SP} * \rho$ & 15.2 & 8 & 75 \\
$V_{\mathrm{f}}$ & 44.2 & 9 & 85 \\
$\rho$ & 85.4 & 10 & 95 \\
\hline
\end{tabular}

have significant effect on flexural strength. Other factors and interactions are found to be insignificant at $95 \%$ confidence level.

From the response table, normality plot and ANOVA, the common factors which are significant with respect to the response variable are found to be $\rho, T$ and $V_{\mathrm{f}}$. In other words, the fibre volume fraction, ultimate pyrolysis temperature and the density of the composites need to be maintained at appropriate levels to obtain the desired mechanical strength.

4.4d Development of correlation for predicting average flexural strength: It is evident from the ANOVA and normal probability curve that the interaction effects of the parameters are found to be insignificant. Flexural strength of the specimen depends on many other parameters other than the process parameters. For example, surface finish, span length and local defects affect the flexural strength. In ideal case, if the sample preparation and test conditions are kept similar, then the flexural strength of the PIP-based UD C/SiC composite can be estimated using equation (1). It is assumed that the effect of the factors is linear between the lower and upper limits.

$$
\begin{aligned}
\text { Flexural strength }(\mathrm{MPa})= & \alpha_{0}+\alpha_{1}+\alpha_{2}(T)+\alpha_{3}\left(V_{\mathrm{f}}\right) \\
& +\alpha_{4}(\rho),
\end{aligned}
$$

where $\alpha_{0}, \alpha_{1}, \alpha_{2}, \alpha_{3}$ and $\alpha_{4}$ are constants and SP, T, $V_{\mathrm{f}}$ and are the process parameters (variables) as described in table 1.

The data from tables 2 and 3 are used to determine the values of the constants following the steps/instructions given in the standard in-built MATLAB program 'multiple regression'. Equation (1) can be rewritten as equation (2) after inserting the values of the constants which were obtained from MATLAB program 'multiple regression' output.

$$
\begin{gathered}
\text { Flexural strength }(\mathrm{MPa})=382.37+0.095 *(\mathrm{SP}) \\
-0.285(*)(T)+1.76\left(V_{\mathrm{f}}\right)+236.25 *(\rho) .
\end{gathered}
$$

Errors in flexural strength were least (1.0 MPa) for experiment number 10 and the highest (33 $\mathrm{MPa})$ for experiment number 9.

Equation (2) may be used to estimate the strength for unknown process variables set within their limits described in table 1.

\subsection{Flexural stress and microstructure analysis}

To assess the impact of various important process conditions, stress/strain curves of the specimen with value close to the average value of the given set is plotted and the plotted data are shown in figures 6 and 7 .

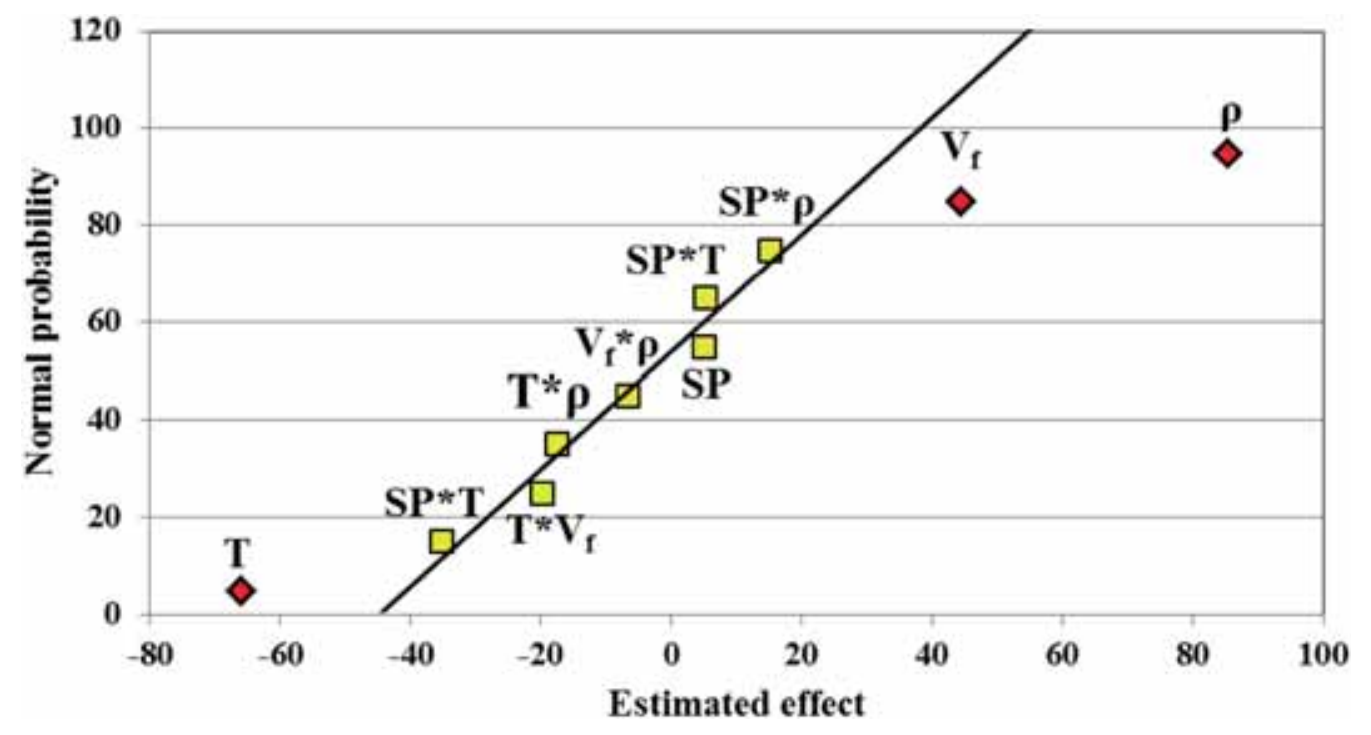

Figure 5. Normal probability plots of the factors. 
Table 6. Analysis of flexural strength-ANOVA two way.

\begin{tabular}{lcccrcr}
\hline Source & Sum Sq. & df & Mean Sq. & \multicolumn{1}{c}{ F } & $P$ & \% Significance \\
\hline SP & 812.25 & 1 & 812.25 & 3.59 & 0.1166 & 1.35 \\
$T$ & 12996 & 1 & 12996 & 57.48 & 0.0006 & 21.60 \\
$V_{\mathrm{f}}$ & 4970.25 & 1 & 4970.25 & 21.98 & 0.0054 & 8.26 \\
$\rho$ & 35721 & 1 & 35721 & 157.99 & 0.0001 & 59.36 \\
SP $* T$ & 110.25 & 1 & 110.25 & 0.49 & 0.5161 & 0.18 \\
SP $* V_{\mathrm{f}}$ & 121 & 1 & 121 & 0.54 & 0.4973 & 0.20 \\
SP $* \rho$ & 930.25 & 1 & 930.25 & 4.11 & 0.0983 & 1.55 \\
$T * V_{\mathrm{f}}$ & 1980.25 & 1 & 1980.25 & 8.76 & 0.0315 & 3.29 \\
$T * \rho$ & 1225 & 1 & 1225 & 5.42 & 0.0674 & 2.04 \\
$V_{\mathrm{f}} * \rho$ & 182.25 & 1 & 182.25 & 0.81 & 0.4104 & 0.30 \\
Error & 1130.5 & 5 & 226.1 & & & 1.88 \\
Total & 60179 & 15 & & & & \\
\hline
\end{tabular}

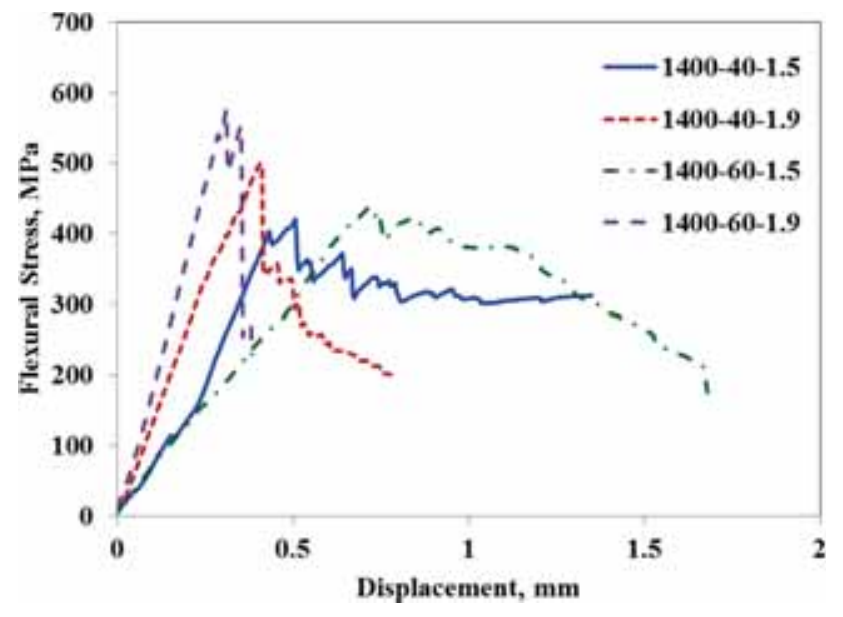

Figure 6. Typical stress/strain curves for the samples pyrolysed at $1400^{\circ} \mathrm{C}$.

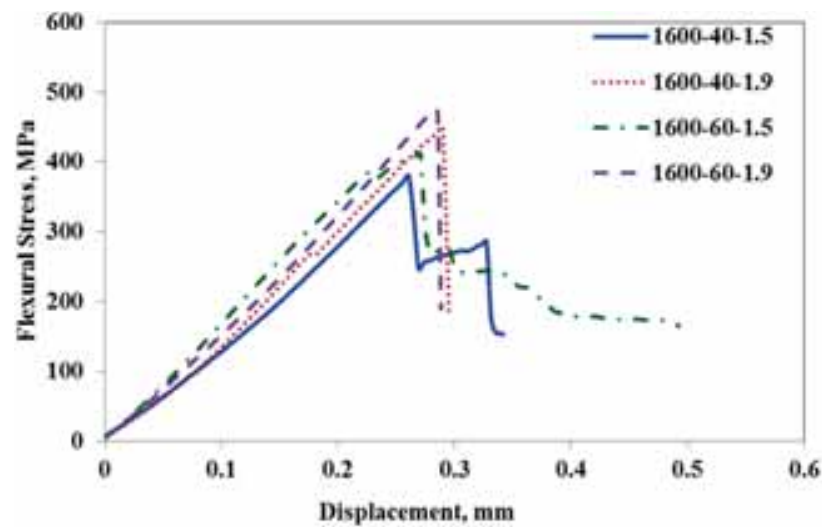

Figure 7. Typical stress/strain curves for the samples pyrolysed at $1600^{\circ} \mathrm{C}$.

4.5a Effects of density and $V_{\mathrm{f}}$ : Typical stress-strain curves correspond to experiment numbers 1, 2, 3 and 4 are plotted and compared (figure 6), while the curves correspond to experiment numbers 13,14, 15 and 16 are compared and shown in figure 7. The title of the series e.g., 1400-40-1.5 shows pyrolysis temperature $\left(1400^{\circ} \mathrm{C}\right)$ - fibre volume fraction $\left(V_{\mathrm{f}}\right)$ in $\%$-density of the composite $(\rho)$ in $\mathrm{g} \mathrm{cm}^{-3}$.

The flexural stress-strain curves of the samples pyrolysed at 1400 and $1600^{\circ} \mathrm{C}$ are found to be quite different. Also, the curves greatly vary with density. Initial slope of the composite pyrolysed at $1400^{\circ} \mathrm{C}$ (figure 7) vary with the density and $V_{\mathrm{f}}$. The composite with $60 \% V_{\mathrm{f}}$ and $1.9 \mathrm{~g} \mathrm{~cm}^{-3}$ density has highest slope, while the samples with $40 \% V_{\mathrm{f}}$ and $1.5 \mathrm{~g} \mathrm{~cm}^{-3}$ density have the least slope. Displacement values corresponding to the failure stress were also different, it is in the following order 1400-60-1.9 $(0.3 \mathrm{~mm})<$ $1400-40-1.9(0.38 \mathrm{~mm})<1400-40-1.5(0.46 \mathrm{~mm})<$ $1400-60-1.5(0.698 \mathrm{~mm})$. Serration in the stress-strain curves indicates the phenomena of crack arresting, branching and/or deflection. It is prominent in specimen pyrolysed at $1400^{\circ} \mathrm{C}$ (figure 7 ). The failure is non-brittle for the composites pyrolysed at $1400^{\circ} \mathrm{C}$, while the ones pyrolysed at $1600^{\circ} \mathrm{C}$, the failure is somewhat brittle in nature (figure 8) particularly, for $60 \% V_{\mathrm{f}}$ samples. It is evident that the matrix failed in steps, and also some fibres have failed along with the matrix. Therefore, at many instances, stress came down sharply followed by crack arrest, which has led non-brittle failure in all the cases. On transfer of the load to the remaining unbroken fibres, the composite strip bear the load till further bulk failure of the fibre tows. However, the curve corresponds to 1400-60-1.5 shows a rather shear dominating failure. At some points, the stress remained constant, while displacement was increasing perhaps due to crack development along the fibre axis. At lower density and high $V_{\mathrm{f}}$, shear dominate failure can be expected as the matrix is very porous and its overall volume occupancy is low, which does not have adequate strength to transfer the load due to its poor bonding with the fibres.

The variation in the strength among the different processing conditions bound to happen due to the different morphological features such as microcracks and fibre/matrix local debonds, which get generated during pyrolysis. These differences are unavoidable due to the CTE mismatch between fibre and matrix, non-uniformity shrinkage and different 

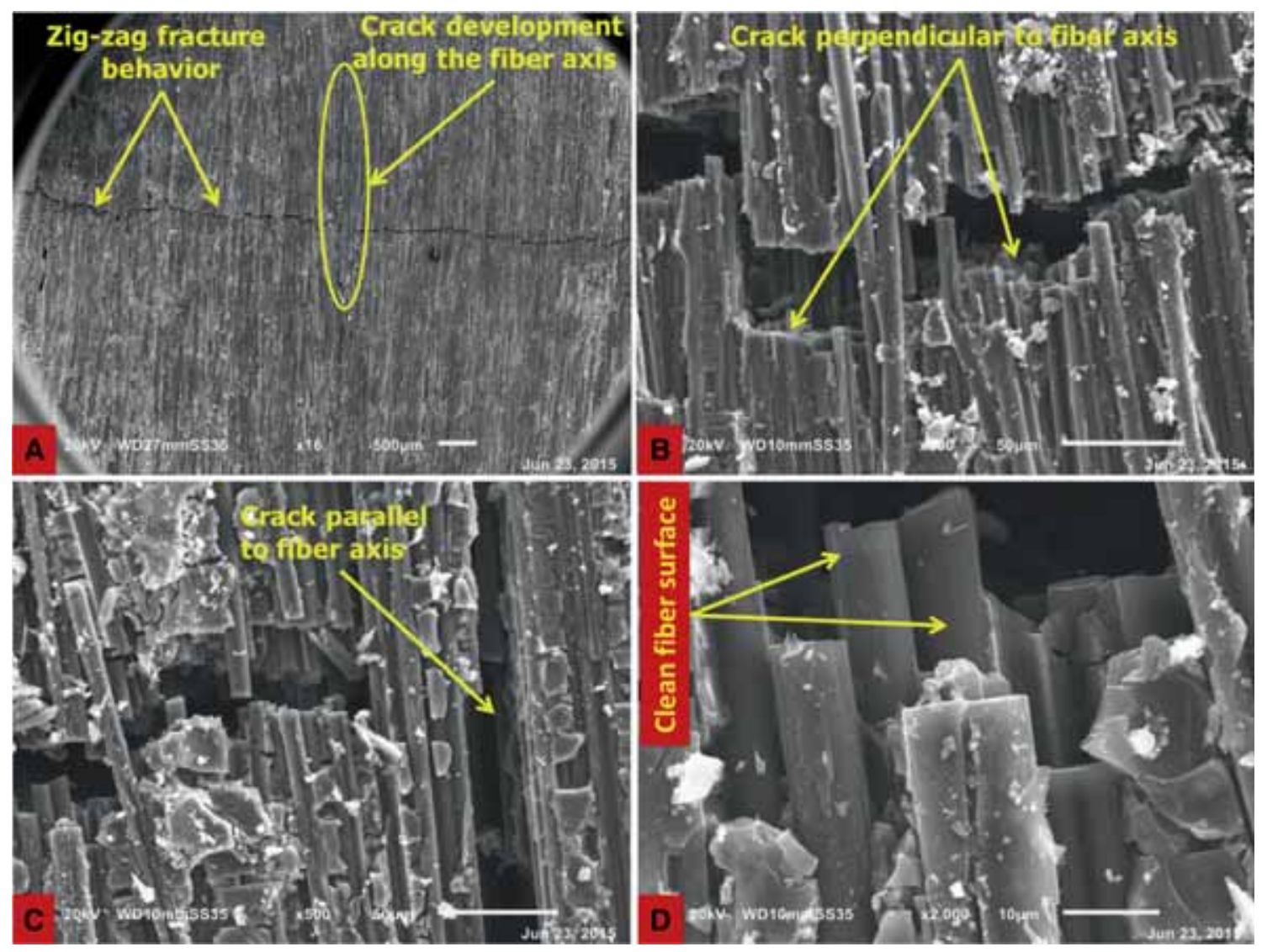

Figure 8. Microstructure of flexural-tested composite pyrolysed at $1400^{\circ} \mathrm{C}$.

thermal stresses because of different $V_{\mathrm{f}}$ and pyrolysis temperatures.

Experimental observations by Karandikar et al [32] show that matrix of the ceramic matrix composites undergo progressive microcracking under load due to which stress and strain become non-linear. UD C/SiC composite can be considered as an assemblage of damaged and undamaged unit-cells consisting brittle and fragmented matrix and continuous fibres. The damage within the cells has matrix cracks transverse to the load direction and unfilled pores created during pyrolysis. As mentioned, due to the thermal mismatch between the fibres and matrix, residual thermal stress gets generated. When CTE of the fibres $\left(\alpha_{\mathrm{f}}\right)$ and matrix $\left(\alpha_{\mathrm{m}}\right)$ is of similar order then, there would be no residual stress $\left(\alpha_{\mathrm{f}}=\alpha_{\mathrm{m}}\right)$. During the loading, debonding occurs prior to that of matrix. On the other hand, residual stress exists if $\alpha_{\mathrm{f}}<\alpha_{\mathrm{m}}$. Since the CTE of the carbon fibres is lower than the CTE of $\mathrm{SiC}[26,27]$, which leads to the residual stress in the composite. The fibre/matrix debonding is proposed to be progressed in the following manner.

4.5b Fibre matrix debonding sequence: At different extension levels, debonding occurred, which is evident from figure 6. Debonding was more prominent for the composites tested at lower density. The occurrence of the first debonding changes the damage map and slope of the curve, which induces the second debonding. As a result of the 2 nd debonding, the damage map is renewed and the subsequent debondings are induced. In this way, the change in damage map due to the preceded debonding causes the next debonding one after another. Due to the progress of the debondings, the stress-carrying capacity of composite is reduced as shown by the stress drop in the stress-strain curves. In this way, the residual stresses change the stress-strain behaviour and variation of the damage map, which affects the strength [33]. Lower density $\left(1.5 \mathrm{~g} \mathrm{~cm}^{-3}\right)$ of PIP-based C/SiC composites have large porosity and therefore, demonstrate low stiffness compared to the high density $\left(1.9 \mathrm{~g} \mathrm{~cm}^{-3}\right)$ samples.

Relatively higher porosity enables debonding processes and thus, composite becomes damage to tolerant. The cracks propagate through the matrix, and can easily deviate close to the fibre surface through the porous matrix. Redistribution of the stresses from the fibre to the matrix does not take place in a significant manner.

It is also evident from table 3, and figures 6 and 7 that at same $V_{\mathrm{f}}$ and density, flexural strength is lower at higher temperature. It is also evident from figure 7 that the samples pyrolysed at $1600^{\circ} \mathrm{C}$ have resulted into relatively brittle failure. It is interpreted due to change in interfacial conditions at $1600^{\circ} \mathrm{C}$. The mechanical behaviour of the weak matrix composite (WMC) is dominated strongly by the properties of 

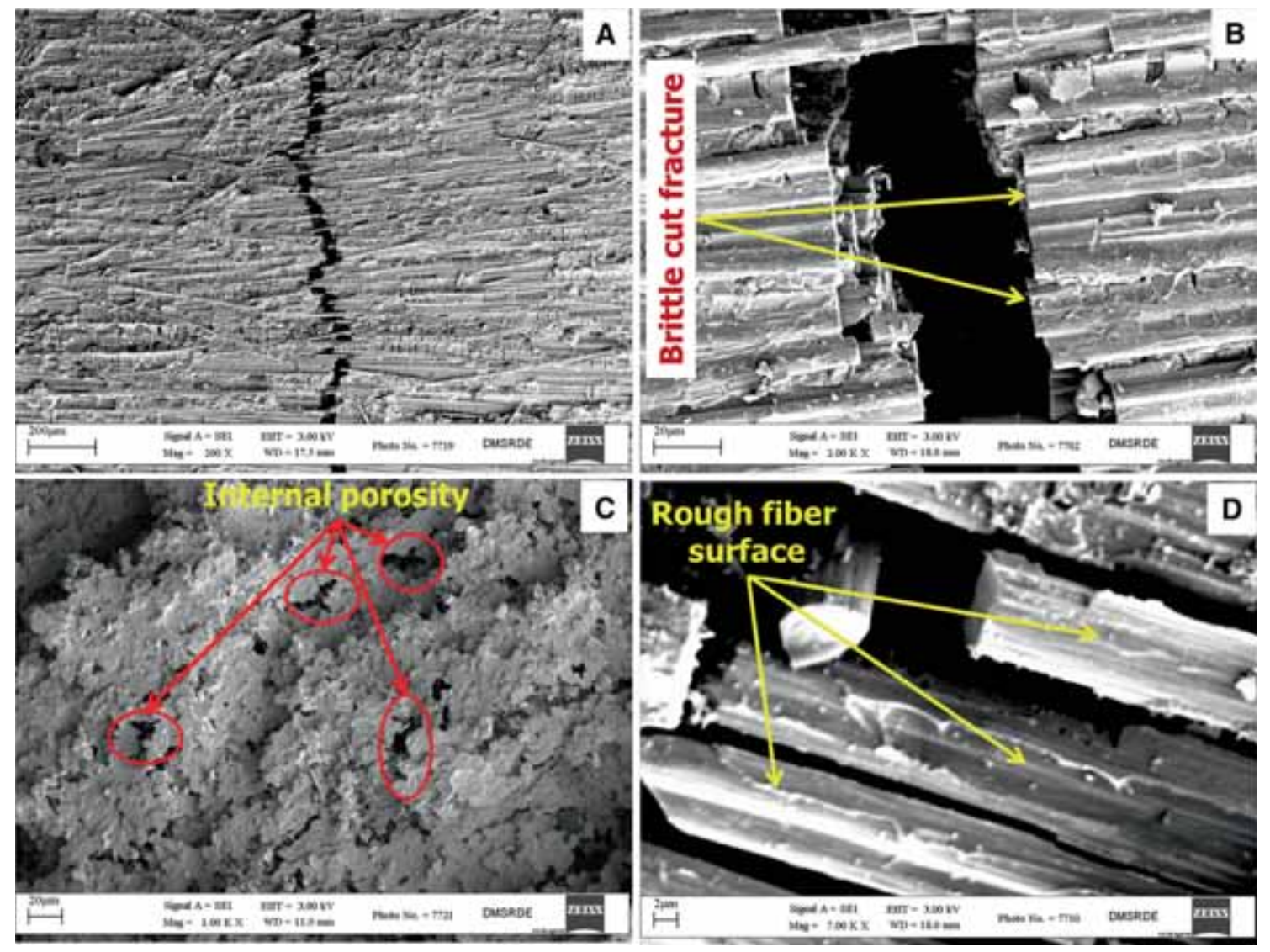

Figure 9. Microstructure of flexural-tested composite pyrolysed at $1600^{\circ} \mathrm{C}$.

the fibres and therefore, the mechanical performance depends on their orientation and the loading direction. This might be the reason for higher strength in $60 \% V_{\mathrm{f}}$ compared to $40 \%$ $V_{\mathrm{f}}$ composites. As the matrix is not able to carry significant applied load, the strength will be under compression and also when the loading is done at an angle with respect to the fibre orientation.

4.5c Effect of temperature: Typical microstructure images of the composite pyrolysed at $1400^{\circ} \mathrm{C}$ are shown in figure $8 \mathrm{a}-\mathrm{d}$, while composites pyrolysed at $1600^{\circ} \mathrm{C}$ are shown in figure $9 \mathrm{a}-\mathrm{d}$. Ultimate pyrolysis temperature and the dwelling time influence the composition and microstructure of the matrix. Temperature and time affect the extent of crystallization, carbothermal reduction reactions and filler reactions when occur in the material. Therefore, the properties at 1400 and $1600^{\circ} \mathrm{C}$ are found to be different. Higher pyrolysis temperature and higher heating rates reportedly improve the mechanical properties [25] when the fibres were protected with $\mathrm{PyC}$ and $\mathrm{SiC}$ nanopins were in situ grown. However, in this study, it was found that the lower temperature yields higher strength compared to higher pyrolysis temperature (figures 6 and 7). It is evident from the stress-strain curves that the failure at $1600^{\circ} \mathrm{C}$ is relatively brittle compared to the composites processed at $1400^{\circ} \mathrm{C}$. From figure $8 \mathrm{a}-\mathrm{d}$, it is evident that the fracture of the composite strip is zig-zag and there are two types of crack patterns viz., (i) perpendicular to the fibre axis and (ii) along the fibre axis. The crack along the fibre axis represents the condition that the bonding between the fibre and matrix is not very strong. The zig-zag crack propagation also demonstrates the crack arresting and deflection along with the fibre pull-out. Simultaneously, occurrence of these events absorbs a lot of energy and ultimately yields higher strength. It is also evident from figure $8 \mathrm{~d}$ that the surface of the pulled out fibres is smooth and does not indicate any chemical reaction between the matrix and fibre.

Crack propagation of the composites processed at $1600^{\circ} \mathrm{C}$ is similar to the ones processed at $1400^{\circ} \mathrm{C}$. However, the image taken at higher magnification (figure 9b) indicates that the fibre matrix bonding for the composite processed at $1600^{\circ} \mathrm{C}$ might have been stronger than the case at $1400^{\circ} \mathrm{C}$. The reinforcing fibre tows have failed in bulk without any visible defection and crack arresting. This observation corroborates with the sudden stress fall (figure 7). It is also observed that the composites processed at $1600^{\circ} \mathrm{C}$ have some internal pores, which have acted as defects and stress concentration points to initiate the failure (figure 9c). It may be explained on the basis that there might be some degradation of fibres at higher temperature in the presence of PCS-generated SiC matrix. 
The carbon fibre surface reaction can takes place at higher temperature $\left(1600^{\circ} \mathrm{C}\right)$ due to $\mathrm{CO}(\mathrm{g})$ evolution from the pyrolysed PCS between 1400 and $1600^{\circ} \mathrm{C}$. The reaction damages the fibre surface (figure 9d) and the fibre matrix bonding appears to be higher and resulted into brittle failure (figure $9 \mathrm{~b}$ ).

\section{Conclusions}

(i) The study would become a base to evolve process parameters to develop PIP-based $\mathrm{C} / \mathrm{SiC}$ composites using carbon fibre tows without employing conventional interface material particularly, for UD composites required for filament wound products.

(ii) Two-level factorial screening design has proved to be an effective tool for studying the effect of individual process parameters and their interaction effects.

(iii) The response table, normal probability curve and ANOVA results show that $\rho, T$ and $V_{\mathrm{f}}$ have strong effect on the flexural strength, while SP of the PCS does not have statically significant effect.

(iv) From the regression analysis, a linear equation was developed, which can be utilized to estimate flexural strength for different combinations of process parameters. The equation would be a handy tool to design the experimental condition to fabricate PIP-based UD $\mathrm{C} / \mathrm{SiC}$ composites of desired mechanical strength.

(vi) The effect of SP was restricted only up to the densification efficiency of the $\mathrm{C} / \mathrm{SiC}$ composites. HSP-PCS could densify the samples in eight cycles, while the LSP-PCS took 11 cycles.

(vii) Composite density found to be very significant with the composite strength and also its effect was very high on the slope of the stress-strain curve. This shows that the composite prepared using PIP should be densified to the desired extent to obtain the required stiffness. $V_{\mathrm{f}}$ has strong effect at lower density, while its effect was marginal at higher temperature and higher density.

\section{Acknowledgements}

We wish to acknowledge the support extended by central characterization facility, DMSRDE, for carrying out TGA and SEM. Funding from DRDO is gratefully acknowledged.

\section{Appendix 1}

\section{A.1. Procedure for estimating fibre volume fraction in the composite sample}

Required number tows of $6 \mathrm{~K}$ carbon fibre are wound to get composite of length ( $L$, length of the each composite sample is fixed to $250 \mathrm{~mm}$ ), width ( $W$, width of the composite samples varied between 5 and $10 \mathrm{~mm}$ ) and thickness ( $t$, thickness of the composite sample was $0.9-1.7 \mathrm{~mm}$ ). Typical scheme of UD composite is shown as figure 10. Fibre volume fraction in the composite samples was estimated using the following formula:

$$
V_{\mathrm{f}}=\frac{n * W t_{1} / \rho_{\text {carbon fiber }}}{L * W * t}
$$

where

$n=$ number of carbon fibre tows wound in the graphite fixture slot and number of tows present in composite sample,

$W t_{1}=$ average weight of a single carbon fibre tow of $250 \mathrm{~mm}$ length $(\mathrm{g})$,

$\rho_{\text {carbon fiber }}=$ the density of carbon fibre in $\mathrm{g} \mathrm{cm}^{-3}$, as per the supplier and manufacturer, density of the T300 carbon fibres is $1.76 \mathrm{~g} \mathrm{~cm}^{-3}$,

$L=$ length of the composite (kept fixed,equal to 250 $\mathrm{mm}$ ),

$W=$ width of the composite,

$t=$ thickness of the composite.

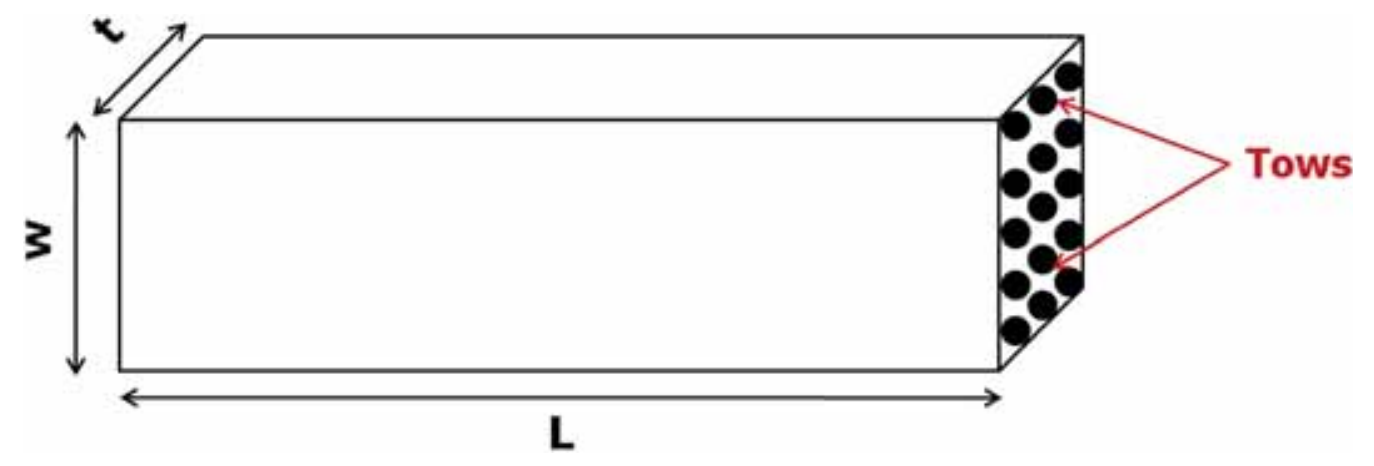

Figure 10. Typical scheme of the UD C/SiC composite sample. 
The following steps were followed to estimate the fibre volume fraction.

Step 1: Average weight of a single 6K carbon fibre tow of $250 \mathrm{~mm}$ length was determined. A long tow of $25 \mathrm{~m}$ length was cut and weighed on a digital balance with least count of $10 \mathrm{mg}$. The weight of $25 \mathrm{~m}$ long tow was divided by 100 to get weight of a $250 \mathrm{~mm}$ long tow. The weight of $250 \mathrm{~mm}$ long, $6 \mathrm{~K}$ carbon fibre tow $\left(W t_{1}\right)$ was found to be $0.088 \mathrm{~g}$.

Step 2: Dimensions of the composite samples was measured using the digital vernier calipers.

Step 3: Using the above formula, the following typical calculations were made to estimate $V_{\mathrm{f}}$ in the final composite samples of length $250 \mathrm{~mm}$. Some typical estimated values are given in the below table.

\begin{tabular}{llllll}
\hline & \multicolumn{5}{c}{ Fibre volume } \\
$n$ & $N * W t_{1}(\mathrm{~g})$ & $\left(\mathrm{cm}^{3}\right)$ & $W(\mathrm{~cm})$ & $t(\mathrm{~cm})$ & $V_{\mathrm{f}}$ \\
\hline 9 & 0.792 & 0.45 & 0.5 & 0.09 & 0.4 \\
17 & 1.496 & 0.85 & 0.5 & 0.17 & 0.4 \\
18 & 1.584 & 0.90 & 1.0 & 0.09 & 0.4 \\
27 & 2.376 & 1.35 & 1.0 & 0.09 & 0.6 \\
34 & 2.992 & 1.70 & 1.0 & 0.17 & 0.4 \\
51 & 4.488 & 2.55 & 1.0 & 0.17 & 0.6 \\
\hline
\end{tabular}

\section{References}

[1] Krenkle W 2005 (ed) N P Bansal Handbook of ceramic composites (Academic Publishers) p 117

[2] Suresh K, Anil K, Sampath K, Bhanu Prasad V V, Chaudhary J C, Gupta A K et al 2013 J. Eur. Ceram. Soc. 312425

[3] Suresh K, Anil K, Ramesh Babu M and Raghvendra Rao M 2015 Int. J. Appl. Ceram. Technol. 12 (Suppl. 3) E176

[4] Schmidt S, Beyer S, Knabe H, Immich H, Meistring R and Gessler A 2004 Acta Astronaut. 55409
[5] Zhao S, Zhou X, Yu J and Mummery P 2013 Mater. Sci. Eng. A 559808

[6] Zhao S, Zhou X and Jinshan Y 2014 Ceram. Int. 403879

[7] Jian K, Chen Z-H, Ma Q-S and Zheng W-W 2005 Mater. Sci. Eng. A 390154

[8] Wu B, Dong S, Wang Z, Kan Y, Zhang L and Zhou F 2013 Ceram. Int. 394729

[9] Jian K, Chen Z-H, Ma Q-S, Hu H-F and Zheng W-W 2007 Ceram. Int. 33905

[10] Liu H, Cheng H, Wang J and Tang G 2010 Ceram. Int. 362033

[11] Rebillat F, Lamon J and Guette A 2000 Acta Mater. 484609

[12] Braginsky M and Przybyla C P 2016 Compos. Struct. 136538

[13] Koch D, Tushtev K and Grathwohl G 2008 Compos. Sci. Technol. 681165

[14] Njoya D and Hajjaji M 2015 J. Asian Ceram. Soc. 332

[15] Jian K, Chen Z-H, Ma Q-S, HuHai F and Zheng W-W 2007 Ceram. Int. $\mathbf{3 3} 73$

[16] Luo Z, Zhou X, Yu J, Sun K and Wang F 2014 Ceram. Int. 40 1939

[17] Yin J, Lee S-H, Feng L, Zhu Y, Liu X, Huang Z et al 2015 Ceram. Int. 414145

[18] Ma C, Guo L, Li H, Tan W, Duan T, Liu N et al 2016 Des. 90 373

[19] Zhao S, Zhou X and Yu J 2014 Ceram. Int. 403879

[20] Sreeja R, Swaminathan B, Anil P, Sebastian T V and Packirisamy S 2010 Mater. Sci. Eng. B 168204

[21] Yang B, Zhou X and Yu J 2015 Ceram. Int. 414207

[22] Wang H, Zhu D, Mu Y, Zhou W and Luo F 2015 Ceram. Int. 4114094

[23] Palanikumar K and Karthikeyan R 2007 Mater. Des. 281584

[24] Saxena A K, Ashok R, Rajesh Kumar T and Mathur G N 2011 Indian patent no. 249015

[25] Kumar S, Misra M K, Mondal S, Gupta R K, Mishra R, Ranjan A et al 2015 Ceram. Int. 4112849

[26] Praderea C and Sauder C 2008 Carbon 461874

[27] Li Z and Bradt R C 1986 J. Mater. Sci. 214366

[28] Yoshio H 1989 J. Mater. Sci. 241177

[29] Lochner R H and Mater J E 1990 Designing for quality (London: Chapman and Hall)

[30] Miller I and Freund J E 1985 Probability and statistics for engineers (New Delhi, India: Prentice Hall of India)

[31] Karandikar P G and Chou T-W 1992 Ceram. Eng. Sci. Proc. 13881

[32] Ochiai S, Tanaka M, Tanaka H, Kimura S and Hojo M 2002 Compos.: A 331337

[33] Koch D, Tushtev K and Grathwohl G 2008 Compos. Sci. Technol. 681165 